\title{
Sistemas de informação em políticas sociais descentralizadas: uma análise sobre a coordenação federativa e práticas de gestão
}

\author{
Lya Cynthia Porto de Oliveira \\ Escola de Administração de Empresas de São Paulo - Fundação Getulio Vargas \\ Sarah Martins Faleiros \\ Escola de Cidadania e Política \\ Eduardo Henrique Diniz \\ Escola de Administração de Empresas de São Paulo - Fundação Getulio Vargas
}

\begin{abstract}
Este artigo objetiva avaliar como sistemas de informação criados pelo governo federal brasileiro são utilizados para coordenar políticas sociais descentralizadas em três áreas - saúde, educação e assistência social — em que políticas públicas federais são implantadas em parceria com governos estaduais e municipais. Como parte deste estudo, foram realizadas 35 entrevistas semiestruturadas realizadas entre o final de 2012 e início de 2013 com gestores dos três programas estudados e nos três níveis de governo. Além disso, como informação complementar, coletamos 432 questionários que foram respondidos por usuários dos mesmos sistemas. Como referencial teórico para análise, utilizamos um modelo multinível construído a partir da combinação de três teorias — social construtivismo, contextualismo e estruturacionismo - e que vem sendo utilizado em vários estudos relacionados com o uso de sistemas de informação com finalidade social. O estudo conclui que sistemas desenvolvidos considerando a participação dos diferentes níveis de governo tendem a ter melhor aceitação por parte dos usuários e assim produzir melhores efeitos nos resultados das políticas aos quais estão associados. Os sistemas desenvolvidos de forma menos participativa tendem a focar exclusivamente a necessidade de controle pelo governo federal, subaproveitando seu potencial como instrumento de gestão e produzindo menor efeito de controle social da política pública a que está associado. Consequentemente, estes sistemas menos participativos têm menor relevância para a coordenação federativa.
\end{abstract}

Palavras-chave: gestão pública; sistemas de informação; políticas sociais descentralizadas; coordenação federativa.

DOI: http://dx.doi.org/10.1590/0034-76121675

Artigo recebido em 2 ago. 2013 e aceito em 24 jul. 2014

(cc) BY-NC

Uma versão anterior deste artigo foi aceita para apresentação no grupo "Public Administration, Technology and Innovation" do congresso do European Group for Public Administration (EGPA), realizado na Universidade de Edimburgo, Escócia, entre os dias 11 e 13 de setembro de 2013. 
Los sistemas de información en las políticas sociales descentralizadas: un análisis acerca de la coordinación federativa y las prácticas de gestión

Este artículo tiene como objetivo evaluar cómo se utilizan los sistemas de información creados por el gobierno federal de Brasil para coordinar las políticas sociales descentralizadas en tres áreas — salud, educación y trabajo social — en el que se aplican las políticas federales en colaboración con los gobiernos estatales y locales. Como parte de este estudio, se llevaron a cabo 35 entrevistas semi-estructuradas con los directivos de los tres programas de estudio y los tres niveles de gobierno. Además, como información complementaria, se recogieron 432 cuestionarios que fueron completados por usuarios de estos sistemas. Como marco teórico para el análisis, se utilizó un modelo construido a partir de la combinación de tres teorías - constructivismo social, contextualismo y estruturacionismo - y que se ha utilizado en varios estudios relacionados con el uso de sistemas de información con finalidad social. El estudio concluye que los sistemas desarrollados teniendo en cuenta la participación de los diferentes niveles de gobierno tienden a tener una mejor aceptación por los usuarios y por lo tanto producir mejores efectos en los resultados de políticas a las que están asociados. Los sistemas desarrollados de forma menos participativa tienden a centrarse exclusivamente en la necesidad de control por parte del gobierno federal, subaproveitando su potencial como herramienta de gestión, y producir menor efecto de control social de la política pública que se asocia. En consecuencia, estos sistemas menos participativos tienen menos relevancia en la coordinación federal.

Palabras clave: gestión pública; sistemas de información; políticas sociales descentralizadas; coordinación federativa.

Information systems in decentralized social policies: an analysis of the federal coordination and management practices

This article aims to assess how information systems created by the Brazilian federal government are used to coordinate decentralized social policies in three areas - health, education and social assistance - in which federal public policies are implemented in partnership with state and local governments. As part of this study, 35 semi-structured interviews with managers of the three programs studied were held and in the three levels of government. In addition, as supplementary information, 432 questionnaires were collected and they were answered by users of these systems. As a theoretical model for analysis, we used a multilevel model based on the combination of three theories - social constructivism, contextualism and structuracionism - which has been used in several studies related to the use of information systems designed for social purpose. As main findings of this study, we conclude that systems that were developed considering the participation of the different levels of government tend to have better acceptance by users and thus, produce better effects in policy outcomes to which they are associated. Systems developed with less participatory pratices tend to focus exclusively on the need for control by the federal government, not taking advantage of its potential as a management tool, and thus being less effective in making social control of the public policy to the one it is associated. Hence, these less participative systems are less relevant for the federal coordination.

KEYWORDs: public management; information systems; decentralized social policies; federal coordination. 


\section{Introdução}

Com a redemocratização no final da década de 1980 e a Reforma do Estado na década de 1990, a estrutura federativa brasileira foi sendo transformada por meio de diversos processos, dentre os quais a descentralização das políticas públicas. Acompanhando essas mudanças, houve um movimento pela melhoria da gestão pública e valorização do planejamento introduzindo conceitos como eficiência (fazer mais com menos), eficácia (atingir metas e objetivos) e efetividade (resultados e impactos das ações estatais). Ao mesmo tempo, a democratização levou a uma maior pressão por participação social, transparência, prestação de contas e accountability na agenda governamental.

A descentralização, no entanto, pode também implicar o aprimoramento das disparidades inter e intrarregionais, especialmente se o governo federal não atuar de forma a compensar as desigualdades regionais (Souza, 2002). Para evitar isso, a instância federal deve exercer um forte papel na regulação e na coordenação das políticas públicas nacionais de forma a colaborar com as necessidades das esferas locais, diminuindo as desigualdades regionais (Arretche, 1996). É importante, porém, que haja um equilíbrio entre coordenação federativa e autonomia local, para que os governos subnacionais possam formular e implantar políticas de acordo com suas necessidades e especificidades locais (Abrucio, 2010).

Os sistemas de informação agregam os fatores humanos e organizacionais à tecnologia de informação, esta referindo-se aos aparatos tecnológicos, que são responsáveis pela captura, armazenamento, transmissão e manipulação de informação, geralmente no formato digital. Analisando seu uso no setor público, em particular, os sistemas de informação têm sido considerados ferramenta estratégica para melhorar a eficiência dos serviços públicos, gerando maior economia para o estado, maior nível de transparência e mais qualidade no atendimento das demandas dos cidadãos. Embora haja um número muito grande de estudos que focam o uso de sistemas de informação para a melhoria dos processos de gestão e controle em todos os níveis de governo, há um número bem menor de estudos que focam os sistemas de informação como instrumentos para a coordenação federativa.

Este estudo tem como principal objetivo analisar a eficácia dos sistemas de informação como elemento de coordenação federativa, avaliando também os processos de gestão, controle e transparência relacionados com o uso de três sistemas de informação implantados a partir de 2008 no Brasil: o Sistema Hórus, na área da Saúde, o Sisjovem, na área de Assistência Social, e o PDE Interativo, na área da Educação.

Entende-se que a análise da forma como esses sistemas são desenvolvidos e negociados com os entes federados pode contribuir para entender os resultados desses sistemas como instrumentos promotores de coordenação federativa, de controle social e de uma gestão mais eficiente e transparente dos programas sociais. A análise realizada busca evidências para comprovar duas hipóteses. A primeira é que sistemas que possuem processos de negociação mais participativos costumam ter melhores resultados, são mais apropriados por seus usuários e, por consequência, melhores ferramentas de coordenação federativa. A segunda é que sistemas de informação que focam apenas o controle formal da execução de regras de programas con- 
cebidos por esferas superiores da federação possuem resultados mais restritos do que aqueles que procuram ser instrumentos de gestão para os entes responsáveis pela implantação dos programas.

\section{Sistemas de informação na gestão pública}

O fenômeno da utilização dos sistemas de informação como instrumento de coordenação federativa é recente no Brasil. Durante a revisão da literatura encontramos, separadamente, estudos sobre o federalismo (Abrucio, 2010; Obinger, Leibfried e Castles, 2005; Rocha e Faria, 2004) e Tecnologias da Informação e Comunicação (TICs) articuladas a diversos assuntos governamentais e administrativos (Diniz et al., 2009; Thurston, 2012; Jorna e Wagenaar, 2007). Foram poucos aqueles que trataram diretamente da imbricação entre relações federativas e sistemas de informação (Bovens e Zouridis, 2002) como esta pesquisa propõe.

A preocupação com o investimento em TICs no setor governamental do Brasil nasce simultaneamente ao processo de modernização da administração pública impulsionado pela reforma do Estado em 1995, no qual as diretrizes de eficiência, eficácia, transparência, controle e prestação de contas tornaram-se centrais (Diniz et al., 2009). Para alguns autores, além dos ganhos em eficiência, as TICs e os sistemas de informação surgem como ferramentas para que a gestão pública sofra menos interferências políticas. Ao introduzir as TICs e os sistemas de informação, reduzir-se-ia substancialmente o poder dos agentes públicos em geral, mas especialmente daqueles que têm contato direto com os usuários nas agências que disponibilizam serviços públicos aos cidadãos — os burocratas de nível de rua (Lipsky, 1980), como é o caso dos usuários dos sistemas que são analisados neste trabalho.

No entanto, dependendo da gestão dos sistemas de informação na administração pública, sua utilização pode enrijecer a discricionariedade pública e até mesmo não trazer ganhos de eficiência. As ações dos burocratas de nível de rua, responsáveis pela implementação das políticas, estão sujeitas a inúmeras regras e procedimentos impostos pelas políticas públicas formuladas e pelas legislações, que buscam estruturar a maior parte de suas escolhas. Todavia, características do ambiente em que esses agentes trabalham podem influenciar e até incentivar a discricionariedade. Ao padronizar o processo de tomada de decisões dos burocratas, propondo a interpretação "correta" ou oficial da lei, os sistemas de informação podem reduzir demasiadamente o escopo dessa discricionariedade, introduzindo maior disciplina hierárquica nas organizações públicas. Em alguns casos, os burocratas de nível de rua podem perder seu papel primordial, limitando-se a auxiliar os usuários dos serviços públicos a preencherem os formulários. Há casos, entretanto, em que o sistema liga os usuários diretamente aos tomadores de decisão, tornando os burocratas de nível de rua completamente dispensáveis (Bovens e Zouridis, 2002; Jorna e Wagenaar, 2007).

No entanto, espera-se que os agentes públicos, ou burocratas de nível de rua, tenham a capacidade de tomar decisões que sejam adequadas à situação específica vivenciada. Por mais que as leis e regulamentações sejam detalhadas, é pouco provável que consigam in- 
corporar todas as situações da realidade, que é sempre muito mais complexa. Os agentes públicos lidam com seres humanos e podem responder mais adequadamente à situação concreta e específica de cada caso, indo além das respostas padronizadas que os sistemas em geral proporcionam.

No caso do federalismo brasileiro, em que o governo federal ainda é responsável por planejar grande parte das políticas públicas, o uso cada vez maior de sistemas de informação pode enrijecer seu processo de implementação, realizado, de forma geral, pelos municípios. Dessa forma, esses entes, que já possuem pouco espaço para adaptar as políticas públicas às suas especificidades locais, podem perder parte do seu poder de influência na implementação dessas políticas.

Finalmente, a proliferação indiscriminada de sistemas, sem a devida capacitação de seus usuários, pode gerar consequências negativas, como a exclusão de atores do processo, ou de cidadãos do acesso aos serviços públicos. Além disso, se os muitos sistemas não se integrarem e não tiverem normas claras de organização das informações, a capacidade de análise dos gestores se verá reduzida, bem como seus potenciais impactos (Thurston, 2012).

\section{Metodologia}

A metodologia utilizada para a realização da análise dos sistemas de informação de políticas sociais descentralizadas é o estudo de caso e análise qualitativa. Três casos foram estudados: (1) o Sistema Hórus - Sistema Nacional da Assistência Farmacêutica, instrumento de planejamento e gestão dos serviços farmacêuticos do SUS; (2) o Sisjovem, sistema responsável por avaliar e controlar a execução das atividades do Programa Projovem Adolescente; (3) e o Sistema PDE Interativo, instrumento de planejamento e gestão do Programa de Desenvolvimento da Escola (PDE Escola).

Para isso, foram utilizadas quatro fontes de dados: (1) coleta de dados extraídos da análise dos sistemas, seus manuais e outros materiais disponibilizados nos sites dos programas na internet; (2) entrevistas em profundidade a partir de roteiro semiestruturado realizadas com os gestores dos programas analisados nos três níveis de governo - federal, estaduale municipal; (3) observação e entrevista sobre o uso dos sistemas pelos usuários; e (4) aplicação de questionários estruturados via internet respondidos por usuários dos sistemas que são gestores dos programas no nível local.

Para a realização do levantamento de campo, foram selecionados os estados do Pará e de São Paulo, por terem contextos socioeconômicos bastante diferentes, e diferenças substancias quanto ao acesso à internet, além da diversidade no contexto das políticas públicas nas áreas cobertas pelos programas estudados. Em cada estado, selecionaram-se três cidades com perfis diferentes para a realização das entrevistas com gestores municipais. Neste caso, foram selecionadas as duas capitais dos estados e também municípios menores, cobrindo assim tanto localidades com maior adensamento populacional e melhor acesso à infraestrutura quanto outras com menor população e acesso limitado à internet e informações do governo federal. 
Além disso, um critério essencial foi a escolha de municípios que tivessem aderido aos três sistemas estudados, uma vez que essa adesão é espontânea.

No caso do sistema Hórus, foi selecionado um caso de controle (Goertz, 2006) — referente ao município de São Paulo, que possui um sistema de assistência farmacêutica próprio - para que fosse possível compreender as principais diferenças entre municípios que utilizam o sistema investigado (Hórus) e municípios que não adotaram o padrão do sistema federal. O quadro 1 apresenta a lista indicando o nível federativo dos entrevistados e o número de respondentes do questionário on-line para cada sistema investigado:

Quadro 1

Entrevistas realizadas por sistema e nível de governo

\begin{tabular}{|c|c|c|c|}
\hline Entrevistas realizadas & Hórus & PDE Interativo & SISJOVEM \\
\hline Governo Federal & 1 & 1 & 2 \\
\hline Governo Estadual São Paulo & 0 & 1 & 1 \\
\hline Governo Estadual Pará & 0 & 1 & 1 \\
\hline Governo Municipal - Belém (PA) & 1 & 1 & 1 \\
\hline Governo Municipal - Ananindeua (PA) & 2 & 1 & 1 \\
\hline Governo Municipal - Augusto Corrêa (PA) & 1 & 1 & 1 \\
\hline Governo Municipal - Registro (SP) & 1 & 0 & 0 \\
\hline Governo Municipal - Diadema (SP) & 1 & 0 & 1 \\
\hline Governo Municipal - São Paulo (SP) & 1 & 0 & 1 \\
\hline Governo Municipal - Juquitiba (SP) & 0 & 1 & 1 \\
\hline Escolas Entrevistadas & 0 & 10 & 0 \\
\hline Total & 8 & 17 & 10 \\
\hline Respostas dos usuários dos sistemas no questionário on-line & 39 & 223 & 170 \\
\hline
\end{tabular}

Fonte: Elaboração própria.

Os questionários aplicados via internet tiveram o objetivo de capturar um número maior de respostas entre os usuários finais do sistema, que são gestores que trabalham na ponta dos serviços públicos, como farmacêuticos, diretores escolares e assistentes sociais, em geral encarregados de gerir os respectivos programas no nível local. No sistema do PDE Interativo obtivemos 223 respostas de 25 estados brasileiros e uma do Distrito Federal. Neste caso, o apoio da equipe do Ministério da Educação (MEC) para disponibilizar os questionários no site do PDE Escola foi fundamental para conseguir o alto número de respondentes. No Sisjovem, 170 pessoas de 23 estados e do Distrito Federal responderam. Neste caso, a equipe do Sisjovem disponibilizou a lista de e-mails dos usuários cadastrados em todo o Brasil. No caso do Hórus, foram obtidas apenas 39 respostas, pois, além de o número absoluto de usuários ser inferior, os questionários só foram enviados para os usuários nos municípios do estado do Pará e de 
São Paulo, pois o Ministério da Saúde (MS) não disponibilizou a lista de e-mails de todos os municípios que aderiram ao Hórus no Brasil.

A análise das entrevistas e respostas dos questionários foi realizada de forma estritamente qualitativa, embora com uso de estatística básica para descrever a percepção dos sistemas na visão dos seus usuários diretos. Toda a coleta e análise dos dados foi feita com base no referencial teórico descrito a seguir.

\section{Referencial teórico}

Para compreender a relação entre sistemas de informação, gestão e coordenação federativa, foi utilizado como referencial o "modelo multinível" apresentado nos trabalhos de Pozzebon, Diniz e Jayo (2009), entre outros. Segundo os autores, esse modelo foi construído com base em três perspectivas teóricas: o estruturacionismo em sistemas de informação (Orlikowski, 2000; Walsham, 2002), os conceitos de formação social da tecnologia, com base no social construtivismo (Bijker e Law, 1992), e o contextualismo (Pettigrew, 1990). Ainda segundo os autores, essas três correntes de pensamento, além de partilharem uma série de pressupostos ontológicos e epistemológicos, foram combinadas, porque cada uma oferece conceitos particulares de grande valor para estudos de sistemas da informação em níveis que vão além de uma organização, como é o caso do apresentado neste artigo.

Este modelo multinível tem sido adotado por diversos pesquisadores que estudam impactos sociais em sistemas de informação (ver detalhamento de uso do modelo e lista de pesquisas em que o modelo foi utilizado em Pozzebon e Diniz, 2012). Segundo os autores, pode-se organizar um processo de coleta de dados em estudos deste tipo por meio dos seguintes procedimentos, geralmente, em sequência:

1) Dimensão Contexto: Identificação dos grupos sociais relevantes de interesse e caracterização dos quadros interpretativos dominantes que determinam a percepção dos sistemas analisados para cada um dos grupos envolvidos (gestores públicos nos diversos níveis federativos);

2) Dimensão Processo: Análise de um processo de negociação envolvendo todos os grupos envolvidos no processo de desenvolvimento (incluindo aspectos regulatórios), implantação e operação dos sistemas;

3) Dimensão Conteúdo: Conclusões ou considerações sobre a tecnologia resultante na prática, com base no que efetivamente se observa da operação dos sistemas a partir da visão dos distintos grupos envolvidos.

Esse modelo permite analisar a relação entre a visão dos grupos sociais envolvidos no uso dos sistemas, o processo de negociação entre eles e seu efetivo resultado. A utilização desse modelo conceitual permite entender e descrever a relação entre os diversos entes federativos na construção dos sistemas de informação para monitoramento de políticas públicas, capturando 
processos em que negociações mais ou menos participativas, conflituosas ou hierarquizadas produzem resultados diferentes no que se refere ao uso e à adoção desses sistemas.

\section{Apresentação dos resultados e análise dos casos}

Os três sistemas analisados neste estudo exemplificam um fenômeno relativamente recente na administração pública brasileira, que tem sua origem nos modelos de reforma gerencial para legitimação do estado social a partir da segunda metade dos anos 1990 (Bresser-Pereira, 2010). Os sistemas estudados foram criados entre 2008 e 2010 e ainda estão em evolução, pois constantes mudanças foram relatadas, evidenciando um processo ainda de adequação às necessidades dos usuários ou solução de problemas técnicos.

Como vemos no quadro 2, dos três programas analisados, dois (Sisjovem e PDE Interativo) são de adesão obrigatória para quem participa do programa relacionado com eles. Ou seja, os programas só funcionam via sistema e para acessar os recursos federais é necessário aderir ao sistema. Todos os três sistemas foram desenvolvidos pelo governo federal, mas precisam dos outros entes federativos para funcionar, especialmente porque os dados no sistema são alimentados ao nível local.

O PDE Interativo é o sistema que possui mais usuários, por estar ligado à extensa rede integrada ao MEC. O Sisjovem, no âmbito do Ministério do Desenvolvimento Social e Combate à Fome (MDS), tem como usuários os orientadores dos Centros de Referência de Assistência Social (Cras) e técnicos das Secretarias Municipais de assistência social. O Hórus, ligado ao MS, é o que tem menos usuários pela não obrigatoriedade de adesão ao sistema para se ter acesso aos programas de financiamento federal na área de medicamentos.

O quadro 2 detalha a síntese da comparação entre os três sistemas, com a indicação do programa ao qual está associado, seus objetivos, ano de criação do programa e do respectivo sistema, características da adesão, da tecnologia e das ferramentas disponíveis aos usuários, bem como a regulação em que está baseado o programa e o nível de adesão a cada um deles.

Quadro 2

Resumo das principais características dos três programas analisados

\begin{tabular}{|c|c|c|c|}
\hline & SISJOVEM & HÓRUS & PDE INTERATIVO \\
\hline Programa & $\begin{array}{l}\text { Programa Nacional de Inclusão } \\
\text { do Jovem Adolescente }\end{array}$ & $\begin{array}{l}\text { Política Nacional de Distribuição } \\
\text { de Medicamentos }\end{array}$ & $\begin{array}{l}\text { Programa de Desenvolvimento da Escola } \\
\text { (PDE Escola) }\end{array}$ \\
\hline Objetivo & $\begin{array}{l}\text { Promover a integração familiar } \\
\text { e social, a participação cidadã } \\
\text { e permanência na escola } \\
\text { de jovens em situação de } \\
\text { vulnerabilidade social. }\end{array}$ & $\begin{array}{l}\text { "Dar suporte à qualificação } \\
\text { da gestão da Assistência } \\
\text { Farmacêutica na Atenção } \\
\text { Básica." }\end{array}$ & $\begin{array}{l}\text { "Desenvolver uma metodologia inovadora } \\
\text { de planejamento e governança de forma a } \\
\text { melhorar a eficiência, eficácia e efetividade } \\
\text { das iniciativas do MEC, com a integração } \\
\text { dos processos de planejamento e gestão } \\
\text { das políticas e programas educacionais do } \\
\text { Governo Federal." }\end{array}$ \\
\hline
\end{tabular}




\begin{tabular}{|c|c|c|c|}
\hline & SISJOVEM & HÓRUS & PDE INTERATIVO \\
\hline $\begin{array}{l}\text { Ano de criação } \\
\text { do Programa }\end{array}$ & 2008 & 2004 & $\begin{array}{l}1998 \text { (criação do Fundo Escola que } \\
\text { posteriormente deu origem ao PDE Escola) }\end{array}$ \\
\hline $\begin{array}{l}\text { Ano em que } \\
\text { o sistema } \\
\text { passou a ser } \\
\text { utilizado }\end{array}$ & 2010 & 2010 - Piloto; 2011 aberto. & $\begin{array}{l}2009 \text { (primeiro sistema on-line/PDE } \\
\text { Escola) } 2011 \text { (PDE Interativo, adaptação } \\
\text { da primeira versão on-line) }\end{array}$ \\
\hline Adesão & $\begin{array}{l}\text { Obrigatória para quem aderiu } \\
\text { ao Programa. }\end{array}$ & $\begin{array}{l}\text { Não obrigatória; há incentivos } \\
\text { ligados ao repasse de verbas } \\
\text { por meio de outros programas } \\
\text { federais na área de saúde. }\end{array}$ & $\begin{array}{l}\text { Obrigatória para quem aderiu ao } \\
\text { Programa. }\end{array}$ \\
\hline $\begin{array}{l}\text { Tecnologia do } \\
\text { sistema }\end{array}$ & Software Livre & Software Livre & Software Livre \\
\hline Ferramentas & $\begin{array}{l}\text { Manual disponibilizado no site; } \\
\text { apoio e capacitação técnica } \\
\text { pelo MDS e pelos governos } \\
\text { estaduais. }\end{array}$ & $\begin{array}{l}\text { Treinamentos presenciais, } \\
\text { sistema de treinamento on-line. }\end{array}$ & $\begin{array}{l}\text { Manual no site; comitê (nos municípios } \\
\text { e estados) e SEB-MEC auxiliam no } \\
\text { desenvolvimento do plano; Jornada de } \\
\text { Gestão Escolar (formação presencial). }\end{array}$ \\
\hline $\begin{array}{l}\text { Legislação que } \\
\text { regulamenta }\end{array}$ & $\begin{array}{l}\text { Decreto no } 6.629 / 2008 \text { e } \\
\text { Portaria no } 848 / 2010\end{array}$ & $\begin{array}{l}\text { Portaria no } 4.217 \text { de } 28 \text { de } \\
\text { dezembro de } 2010 \text { (apenas um } \\
\text { pequeno artigo - art. 12) }\end{array}$ & $\begin{array}{l}\text { A Resolução no } 22 / 2012 \text { dispõe sobre as } \\
\text { regras do programa e apenas menciona } \\
\text { o sistema. }\end{array}$ \\
\hline $\begin{array}{l}\text { Número de } \\
\text { municípios } \\
\text { que aderiram }\end{array}$ & $\begin{array}{l}3.674 \text { municípios em } 26 \\
\text { estados da União e Distrito } \\
\text { Federal }\end{array}$ & 1.114, em 26 estados da União & $\begin{array}{l}3.834 \text { municípios, em } 26 \text { estados da } \\
\text { União }\end{array}$ \\
\hline $\begin{array}{l}\text { Número de } \\
\text { municípios } \\
\text { que já utilizam }\end{array}$ & Todos & $\begin{array}{l}600 \text { solicitaram a senha do } \\
\text { ambiente de acesso, o que } \\
\text { não significa que o estejam } \\
\text { utilizando. }\end{array}$ & $\begin{array}{l}\text { Todos, mas existem casos em que } \\
\text { as escolas não conseguem terminar } \\
\text { de preencher, ou preencher com a } \\
\text { qualidade necessária, a tempo de } \\
\text { receber os recursos. }\end{array}$ \\
\hline
\end{tabular}

Fonte: Elaboração própria.

A seguir, apresenta-se um breve resumo do sistema e de suas principais funcionalidades seguido de uma introdução dos principais atores envolvidos no processo de desenvolvimento dos sistemas e seus interesses, o que chamamos de dimensão contexto. A dimensão processo detalha a forma como os atores interagiram no processo de desenvolvimento e das decisões que impactaram seu processo de implantação. A dimensão conteúdo será apresentada na próxima seção, em uma análise que compara os resultados dos três sistemas.

\subsection{Sistema Nacional da Assistência Farmacêutica (Hórus)}

O Hórus, Sistema Nacional da Assistência Farmacêutica, foi criado em 2009 pelo Departamento de Assistência Farmacêutica do MS com o objetivo de auxiliar no "planejamento, monitoramento e avaliação das ações de assistência farmacêutica, contribuindo para a ampliação do 
acesso, a promoção do uso racional e a construção dos indicadores nacionais de Assistência Farmacêutica no âmbito do SUS". É um instrumento que o governo federal disponibiliza aos municípios e estados para a gestão da assistência farmacêutica, visando superar a fragmentação e os frequentes problemas desta área, regido pela Política Nacional de Assistência Farmacêutica, instituída em 2004 pelo Conselho Nacional de Saúde (Resolução no 338 do CNS).

O Hórus é hoje composto por três sistemas, a serem integrados futuramente, que correspondem aos três componentes da assistência farmacêutica (Hórus básico, Hórus estratégico, Hórus especializado e Hórus Indígena). Por entender que ainda há pouca experiência acumulada nos módulos Estratégico, Especializado e Hórus Indígena, nossa análise terá foco no Hórus Básico, mencionando os outros sistemas quando for necessário.

O Hórus Básico registra os processos de aquisição, distribuição e controle dos estoques de medicamentos, além de gerar indicadores que permitem ao gestor municipal da assistência farmacêutica planejar a compra de estoques, o remanejamento de produtos entre farmácias ou até municípios, diminuindo a perda por vencimento de validade de medicamentos. Além disso ele registra todas as movimentações de medicamentos até o usuário final. Isso é possível pela integração com o Cartão Nacional de Saúde e o Cadastro Nacional de Estabelecimentos de Saúde.

Inicialmente o sistema foi desenvolvido para ser uma ferramenta de gestão interna aos municípios que o desejassem, conectando os almoxarifados centrais, regionais, farmácias e usuários. Seu projeto original não foi concebido para servir como facilitador da coordenação federativa. Essa necessidade surge aos poucos, primeiramente com o desenvolvimento, em 2011, dos outros "sub" sistemas do Hórus, que permitem o controle dos medicamentos comprados pelos governos estaduais e federal, distribuídos aos municípios - e depois com a integração de ferramentas de webservice e business intelligence (BI). Com essas ferramentas, que seriam concluídas em $2013,{ }^{1}$ espera-se que o sistema seja capaz de gerar indicadores e relatórios sobre a assistência farmacêutica nacional a partir das informações inseridas no sistema pelos municípios.

Atualmente, dos 1.114 municípios que aderiram ao Hórus, apenas 600 pediram a senha do ambiente de produção do sistema, mas nem todos estão ativos.

\subsubsection{Dimensão contexto no Hórus}

Os grupos de atores relevantes para o Hórus são (1) o MS, (2) os órgãos de controle — Controladoria Geral da União (CGU), o Tribunal de Contas da União (TCU) e (3) alguns municípios. O Departamento de Assistência Farmacêutica (DAF) do MS foi o responsável pelo desenvolvimento do Sistema Hórus, que foi desenvolvido por duas motivações: (1) pressão da CGU, que notificou falta de controle dos municípios sobre os recursos enviados pelo governo federal para a compra de medicamentos, incluindo problemas relacionados com o armazena-

\footnotetext{
${ }^{1}$ Esta informação nos foi dada durante a pesquisa realizada em 2012. Não foi possível saber por meio das informações disponíveis no site do Hórus se isso aconteceu e quais foram os resultados.
} 
mento, levando à perda frequente de medicamentos por validade vencida; (2) demanda dos municípios de pequeno porte, que solicitaram ao MS um instrumento de apoio ao controle e gestão dos recursos recebidos do governo federal. O TCU emergiu nas entrevistas como um ator relevante pela sua ação como incentivador da implantação do Hórus em municípios que antes não tinham controle sobre os recursos recebidos. Os estados não foram percebidos como atores importantes no caso do Hórus Básico, que tem como público-alvo primordial os municípios.

\subsubsection{Dimensão processo no Hórus}

O processo de negociação do Hórus privilegiou fóruns institucionalizados representativos das secretarias de saúde municipais e estaduais (Cosens e Conasems), em que as principais decisões relacionadas com a regulamentação e formato geral do sistema foram tomadas. Entretanto, a participação dos municípios neste processo de pactuação aconteceu apenas em relação às regras amplas do sistema, como a obrigatoriedade de adesão. Poucos municípios colaboraram efetivamente no processo de desenvolvimento do sistema. Mesmo entre os 17 municípios-piloto (localizados em 14 estados brasileiros), alguns não chegaram até a implantação completa do sistema, reduzindo a quantidade de sugestões e opiniões de usuários, algo essencial no processo de desenvolvimento de sistemas. De forma geral, o sistema foi ofertado "pronto" para a grande maioria dos municípios brasileiros, que pouco puderam opinar sobre ferramentas que poderiam ser relevantes.

Desta forma, decisões cruciais para o processo de implementação - como o fato de o sistema só poder ser utilizado com internet, não ser compatível com um leitor de códigos de barras, ou não se integrar com outras áreas das prefeituras, como o setor de compras — acabaram explicando a baixa taxa de adesão e efetiva implementação ao sistema. Parte dos municípios não teve interesse por não ter condições efetivas de implementá-lo, seja por não ter a estrutura necessária (como internet nos locais de dispensação), seja por falta de qualificação dos funcionários responsáveis pela área, já que julgaram a formação oferecida pelo ministério pouco efetiva. Outros municípios preferiram outros sistemas existentes no mercado, que respondiam melhor às suas necessidades específicas. Dos 39 municípios que responderam ao nosso questionário, 14 não aderiram ao Hórus. Este é também o caso de São Paulo, que, mesmo pagando pela manutenção de seu atual sistema, acredita que esse custo não é superior aos que existiriam, caso resolvessem mudar para o Hórus.

Essas características e a baixa adesão fizeram com que o processo de regulamentação fosse bastante difícil. O indicativo da disponibilização do Hórus dentro da portaria que regulamenta o Componente Básico da Assistência Farmacêutica² demorou seis meses para ser pac-

\footnotetext{
${ }^{2}$ Art. 12. Para dar suporte à qualificação da gestão da Assistência Farmacêutica na Atenção Básica o Ministério da Saúde disponibiliza aos municípios o Sistema Nacional de Gestão da Assistência Farmacêutica (Hórus).
} 
tuado. Parte dos municípios e estados não queria que o texto expressasse o nome do sistema. Eles tinham duas preocupações. A primeira era que isso possibilitasse interpretações quanto à obrigatoriedade de uso, o que não respeitaria a autonomia de municípios que já possuíam sistemas próprios. A segunda era de que o Hórus fosse mais uma tentativa frustrada do Ministério da Saúde, que após algum tempo e esforço de implementação acabasse sendo abandonado pelo governo federal - como já havia acontecido anteriormente em outros projetos da área.

Outra questão importante nesta dimensão foi a negociação com estados e municípios quanto à obrigatoriedade do envio das informações sobre a gestão da assistência farmacêutica. Isso só foi possível pela ação do TCU que, após observar diversas situações de má gestão dos recursos da assistência farmacêutica, determinou no Acórdão nํㅜ 1.459 de 2011 que o MS investisse na boa gestão desses recursos. Isso deu condições para que a equipe do Ministério da Saúde conseguisse trazer essa questão para a pauta. Esse processo foi feito de forma participativa, por meio da formação de um GT com participantes do Conas e do Conasems, no qual se discutiu a lista mínima de dados que seriam enviados ao ministério. O grupo se reuniu em três oficinas presenciais e duas teleconferências. Esse processo foi finalizado com a publicação da Portaria no 271, de 27 de fevereiro de 2013, que instituiu a Base Nacional de Dados de ações e serviços da Assistência Farmacêutica e regulamentou o conjunto de dados, fluxo e cronograma de envio referente ao Componente Básico da Assistência Farmacêutica no âmbito do Sistema Único de Saúde (SUS).

\subsection{Sisjovem - Sistema do Programa Projovem Adolescente}

O Sisjovem é o sistema de informação criado para auxiliar a gestão do Programa Projovem Adolescente - Serviço Socioeducativo, regulamentado pelo art. 39 do Decreto no 6.629/2008 que integra a Política Nacional de Assistência Social e é executado por meio do Sistema Único de Assistência Social (Suas).

O Projovem Adolescente é uma das modalidades do Programa Nacional de Inclusão de Jovens (Projovem), e tem como público-alvo jovens de 15 a 17 anos em situações de extrema pobreza. Os jovens participantes pertencem a famílias beneficiárias do Programa Bolsa Família e/ou são jovens que participam de programas e serviços de proteção especial. Seu objetivo é promover acesso e permanência na escola, bem como a integração sociofamiliar, comunitária e participação cidadã na vida pública com a finalidade de superar condições de vulnerabilidade social.

O principal objetivo do Sisjovem é realizar o controle da execução das atividades do Programa por meio do envio mensal da frequência dos jovens. Isso porque o repasse dos recursos federais que financiam a execução das atividades no município está vinculado ao número de participantes do Programa. Além disso, os usuários devem preencher semestralmente uma avaliação sobre as atividades desenvolvidas pelo programa. Essa avaliação, no entanto, está mais voltada ao cumprimento dos requisitos formais referentes à estrutura física e material dos espaços de atendimento dos jovens, como a acessibilidade dos espaços para 
deficientes físicos, temas abordados nas atividades etc. As informações disponibilizadas no Sisjovem dizem respeito aos dados sobre cadastramento, frequência escolar dos participantes e execução das atividades do programa.

\subsubsection{Dimensão Contexto do Sisjovem}

Os principais grupos de atores envolvidos na execução do Sisjovem são as secretarias do nível federal, estadual e municipal e os Cras. A Secretaria Nacional de Assistência Social do MDS é responsável no nível federal por sua manutenção e gerenciamento. As Secretarias Estaduais de Assistência Social são responsáveis por monitorar o programa no nível estadual. Já as secretarias ou órgãos responsáveis pela administração dos serviços de assistência social dos municípios participantes do programa seriam responsáveis por auxiliar os funcionários dos Cras, responsáveis pela implantação do Programa e auxiliar os municípios no preenchimento dos dados e atividades realizadas no Sisjovem.

A pesquisa mostrou que as visões e expectativas sobre o sistema são muito diferenciadas entre os entes federativos. O governo federal espera que o sistema seja preenchido pelos responsáveis pelo atendimento do programa nos Cras, e não são percebidos problemas e ineficiências do Sisjovem. Entretanto, na maior parte dos municípios entrevistados se alega que a alimentação de dados no sistema é realizada de forma centralizada na secretaria municipal. Além disso, todos os entrevistados das secretarias estaduais e municipais reclamam de falta de comunicação com o governo federal.

\subsubsection{Dimensão Processo do Sisjovem}

O processo de desenvolvimento do Sisjovem foi hierarquizado e teve pouca participação dos diversos entes federativos nos processos de decisão sobre a forma e objetivos do sistema. Apesar de os técnicos do governo federal alegarem que as discussões sobre o Programa são participativas por meio da consulta com conselhos, nenhum dos entrevistados afirmou ter participado de algum processo deliberativo sobre o sistema e/ou programa com o MDS. As entrevistas mostram que os estados e municípios são apenas comunicados das decisões do governo federal concernentes ao sistema nos espaços de participação formal, mas nesses espaços não há discussão que permita alterar as decisões.

Os municípios são obrigados a inserir os dados exigidos no sistema como requisito de recebimento dos recursos, não havendo concorrência de sistemas diferentes, como acontece no caso do Hórus. Além disso, a regulamentação do sistema é bastante detalhada, o que contribui para a simetria de informações e definição clara do papel de cada ente federativo, mas enrijece a flexibilidade de mudanças do sistema. O resultado é a utilização do sistema como um mecanismo de controle do cumprimento das regras estabelecidas na regulamentação jurídica. 


\subsection{PDE Interativo - O Sistema do Plano de Desenvolvimento da Educação}

O Plano de Desenvolvimento da Escola (PDE Escola) é um dos projetos que compõem o Plano de Desenvolvimento da Educação (PDE). Seu objetivo é desenvolver a gestão escolar das escolas de educação básica e, com isso, melhorar o Índice de Desenvolvimento da Educação Básica (Ideb). Para isso, o PDE Escola fornece uma ferramenta com o objetivo de diagnóstico e planejamento participativo - o sistema PDE Interativo. Em 2013, 19.093 escolas haviam aderido ao PDE Escola, localizadas em 3.834 municípios (o que representa 69\% dos municípios brasileiros) e distribuídas por todos os estados da Federação.

Atualmente, o sistema PDE Interativo é a peça-chave do PDE Escola, e medeia a maior parte do relacionamento entre os atores envolvidos no Programa. Está organizado em etapas que ajudam a equipe escolar a fazer um diagnóstico da situação de sua escola e, a partir dele, construir um plano de ação para enfrentar os principais problemas e desafios existentes. $\mathrm{O}$ plano de ação foca as áreas apontadas como prioritárias pelo PDE Interativo. O sistema foi desenvolvido para interagir permanentemente com o usuário, estimulando a reflexão sobre os temas abordados.

O PDE Interativo também medeia o repasse dos recursos financeiros para as escolas priorizadas - aquelas com avaliações abaixo da média no Ideb. Nesse caso, o repasse só ocorre após a aprovação pelas secretarias estaduais e municipais de educação do plano de ação desenvolvido no PDE Interativo pelas escolas priorizadas. Os recursos vão direto para as escolas e devem ser utilizados para apoiar a execução do todo ou parte das ações planejadas no PDE Interativo. Além disso, desde 2012 qualquer escola, mesmo não priorizada, pode utilizar o PDE Interativo como uma ferramenta de planejamento.

\subsubsection{Dimensão Contexto no PDE Interativo}

No nível federal, a Secretaria de Educação Básica do MEC está diretamente envolvida no PDE Interativo. Nos níveis estaduais e municipais, estão envolvidas as secretarias de Educação e seus respectivos Comitês de Análise e Aprovação, responsáveis pela avaliação dos diagnósticos e planos desenvolvidos pelas escolas de sua rede. As escolas, público-alvo do sistema, constituem o terceiro grupo principal e devem constituir suas Unidades Executoras, associações formalmente constituídas formadas por membros da comunidade escolar, como professores, diretores, pais e alunos.

No caso do PDE, existe uma diferença inicial entre os interesses do MEC e das secretarias e escolas beneficiadas. Enquanto o primeiro grupo quer melhorar a gestão escolar, fazendo com que dirigentes, professores e comunidade escolar conheçam melhor as deficiências das escolas e se planejem para melhorá-las, as escolas e municípios estão, em geral, focados no recebimento dos recursos do programa. No entanto, observou-se que os gestores municipais e escolares conseguem, após utilizar o sistema, reconhecer a importância do planejamento para suas escolas. 


\subsubsection{Dimensão Processo do PDE Interativo}

Entre o final de 2009 e início de 2010, o PDE Escola deixou de ser uma iniciativa do Banco Mundial e passou a ser de estrita responsabilidade do MEC. Desde então, o sistema passa por modificações sistemáticas propostas pelo governo federal, mas feitas de forma participativa, a partir de discussões com os outros atores envolvidos no Programa. A atual versão do PDE Interativo, por exemplo, foi desenvolvida após duas reuniões com a presença de cerca de 80 representantes de todos os estados e capitais.

A participação não ocorre apenas durante o processo de desenvolvimento do sistema, mas de forma permanente. Em média, duas vezes por ano há reuniões para discutir diretrizes, resultados dos programas, propostas e esclarecimentos. Nesses encontros participam apenas representantes das secretarias de educação das capitais e dos estados. Um dos desafios declarados pela equipe do MEC é melhorar a participação dos municípios menores nos processos de desenvolvimento e avaliação do PDE.

Ainda assim, a equipe do MEC tem grande participação nas decisões finais. Um exemplo disso foi a decisão sobre o sistema ser on-line. Quando comparada aos outros casos estudados nesta pesquisa, a área da educação possui mais programas que buscam garantir que seus equipamentos públicos tenham computadores e estejam conectados à internet, ainda que a qualidade dessa conexão não seja boa. Com exceção de uma escola localizada na zona rural de um pequeno município do Pará, todas as escolas visitadas durante a pesquisa tinham computadores e estavam conectadas à internet. Também no Pará, todas as escolas visitadas reclamaram da velocidade da internet e da estabilidade da conexão.

Conhecendo este contexto, a equipe técnica responsável pelo desenvolvimento do PDE Interativo propôs que o sistema pudesse ser off-line. O plano de educação seria enviado apenas ao término do preenchimento do sistema, evitando o retrabalho e a dependência de bom sinal de rede. No entanto, a proposta não foi aceita pela alta gestão do Programa. Para eles, mesmo cientes de todas as dificuldades, deve-se pressionar os órgãos responsáveis para garantir boa conexão. Nas palavras da gestora do PDE no MEC:

E tudo depende de banda e conexão e este é o grande problema. Mas é um caminho sem volta, e não tem alternativa para não utilizar a TI para municípios. Ou a gente torce que o Ministério das Comunicações vai dar um jeito de ampliar o acesso ou os municípios que têm dificuldades de acesso à internet vão ficar para trás. (Entrevista com coordenadores do programa no governo federal, 10 de setembro de 2012)

Outro limite do sistema é que não existe nenhum Help Desk que ajude os usuários a navegar pelo sistema ou denunciar possíveis erros. Por trás dessa decisão está a visão da equipe de TI responsável pelo desenvolvimento. Conforme afirma a gestora do MEC, na visão da equipe de TI, responsável pela elaboração do sistema, o mesmo deve ser perfeito. E se ele é perfeito, não há razão para ter uma central de relacionamento com os usuários. Essa decisão ignora os diferentes graus de intimidade com a tecnologia entre os cerca de 250 mil usuários 
do sistema. Muitos ainda não têm o hábito de utilizar computadores, e por isso possuem ainda mais dificuldade em trabalhar com o sistema. Com isso, quem responde às questões dos usuários é a equipe gestora do PDE Escola, que ficou sobrecarregada. A ausência de um canal de relacionamento entre usuários e responsáveis pelo desenvolvimento enrijece o sistema e dificulta a solução de problemas que de outra forma poderiam ser facilmente resolvidos.

Alguns exemplos da rigidez do PDE Interativo e suas consequências:

v é comum que uma escola não encontre entre as inúmeras opções existentes aquela que corresponda à sua realidade;

v escolas mudam a ação de planejamento que gostariam de fazer, por não encontrar entre as opções oferecidas pelo sistema aquela que desejariam, adequando-se, portanto, ao que é oferecido e deixando de contribuir com sua experiência e particularidades.

Esses fatos demonstram que a rigidez do sistema molda o comportamento de seus usuários. Reconhecer que o sistema, por melhor que seja, não consegue cobrir a enorme diversidade de realidades brasileira e possibilitar que o usuário diga quando o sistema não permite que ele tome uma decisão que gostaria é uma atitude importante, que a equipe responsável pelo sistema poderia ter.

\section{Dimensão Conteúdo dos sistemas estudados}

A partir do que foi observado nos processos de negociação entre os diversos grupos envolvidos nos sistemas estudados, nesta seção apresenta-se a dimensão conteúdo. Ela diz respeito aos resultados dos sistemas decorrentes das visões e negociações dos atores responsáveis pelo seu desenvolvimento, implantação e operação.

A análise da dimensão processo dos três sistemas revelou diferenças importantes entre os mesmos. De forma geral, verificaram-se três comportamentos, que variam de processos mais hierarquizados a processos mais participativos, determinando seus resultados. O Sisjovem foi o caso estudado que contou com menos participação dos envolvidos na construção do sistema. De forma geral, as decisões estiveram centralizadas no MDS e foram apenas comunicadas nas instâncias representativas dos municípios e estados, nos Conselhos de Assistência Social. O Hórus teve momentos de negociação, também dentro de instâncias formais de representação das secretarias municipais e estaduais de saúde, em que as regras gerais do sistema, especialmente sua não obrigatoriedade, foram acordadas. No entanto, esses atores tiveram pouco espaço no processo de desenvolvimento das regras do sistema, gerando um sistema que, pela baixa adesão até o momento estudado, mostra pouca adequação à necessidade ou realidade de seu público-alvo. O PDE Interativo destaca-se pelos processos participativos continuados de avaliação e transformação do sistema como parte de seu público-alvo, o que, como veremos, gerou um sistema mais responsivo à necessidade dos municípios. 
Nesta seção os resultados destes sistemas serão analisados, em três aspectos: sistemas como ferramentas de gestão e planejamento, controle, transparência e coordenação federativa.

\subsection{Instrumentos de gestão}

Os sistemas analisados neste estudo são, em maior ou menor grau, instrumentos de gestão. Tanto no caso do Hórus, como no Sisjovem, os sistemas permitem maior controle na melhor gestão dos recursos da assistência farmacêutica e na implementação do Programa Projovem Adolescente. Já o PDE Interativo proporciona uma melhor gestão ao disponibilizar ferramentas que possibilitam a análise da realidade escolar, identificando pontos deficientes em que a ação planejada é necessária.

No caso do Sisjovem, o foco do sistema é no controle da presença dos jovens. O fato de exigir o lançamento dos dados relativos à participação dos adolescentes no sistema faz com que os gestores municipais do Projovem analisem minimamente as ações do Programa, mas essa análise é rasa, e pouco permite reflexões mais profundas sobre os resultados das ações realizadas e o impacto delas nas vidas dos jovens envolvidos no Programa.

Todos os gestores municipais e estaduais entrevistados afirmaram que o PDE Interativo contribui para a gestão escolar e melhora da qualidade de ensino. Também houve 33 menções à contribuição do sistema para a gestão e qualidade de ensino entre as 223 respostas do questionário on-line. As entrevistas com as escolas mostram que o sistema é uma ferramenta potente de análise da realidade escolar. Percebe-se que, a partir do preenchimento do sistema, as escolas passam a dominar melhor seus indicadores, refletir sobre assuntos levantados pelo sistema e traçar metas de melhorias.

No caso do Hórus, mesmo os municípios que acabavam de implantar o sistema, e apenas no almoxarifado central, como é o caso de Ananindeua (PA) e Registro (SP), relatam que o controle sobre a distribuição dos medicamentos melhorou, as perdas por validade diminuíram, entre outros resultados positivos. Com as informações em mãos, conseguem se planejar melhor, diminuindo os riscos de desabastecimento ou desperdícios.

É importante ressaltar, no entanto, que apesar destes sistemas serem instrumentos importantes, para que seus impactos sejam maiores, é preciso que os funcionários que trabalham diretamente com eles sejam bem capacitados e possam não apenas lançar os dados no sistema, mas refletir sobre eles e sobre como eles traduzem a realidade vivenciada. Como são os responsáveis por lançar os dados no sistema, poderiam também identificar situações em que o sistema não está se adequando à situação real, devendo saber como proceder nesses casos. A gestora responsável pela implantação do Hórus em Diadema (SP), por exemplo, afirmou que analisa os relatórios gerados pelo sistema semanalmente: "Entro constantemente no Hórus, porque acho que o sistema só funciona se tem alguém monitorando". Quando percebe alguma diferença, no estoque, por exemplo, entra em contato com a UBS responsável. Os funcionários sentiram o controle maior, e tiveram de mudar seus hábitos de trabalho. 


\subsection{Controle}

Um dos objetivos de grande parte dos sistemas de informação de políticas públicas descentralizadas é o controle da implantação dessas políticas no nível local. Nos estudos de caso apresentados, os processos e objetivos do controle são diferentes entre os sistemas analisados.

O controle é a grande finalidade do Sisjovem, que busca comprovar se as ações desenvolvidas estão conformes às regras estabelecidas na Portaria no 848/2010 que o regulamenta. Durante a pesquisa de campo foi possível perceber que, embora seja possível fraudar as informações inseridas no sistema sobre a frequência de jovens nos coletivos, o Sisjovem auxilia na possível identificação dessas fraudes, desde que exista alguém que analise os dados enviados. Alguns dos entrevistados relataram casos em que a análise dos dados inseridos no sistema mostrou que os coletivos estavam sendo fraudados. Ao focar o controle formal, como a frequência dos jovens nos coletivos, não se aproveita seu potencial como instrumento de gestão e de avaliação da qualidade da execução de suas atividades, como afirma uma das entrevistadas:

o sistema não nos dá ainda informações sobre as dificuldades que cada município está tendo para conseguir preencher estas normas. (...) Uma coisa que o MDS sempre fala para nós é que o Sisjovem é um sistema pensado em cima da legislação, ele é superfechado. (Entrevista na Secretaria Estadual de Assistência Social de São Paulo, 13 de dezembro de 2012)

No caso do Hórus, o controle é uma variável que ganha importância. Inicialmente havia sido criado para ser um instrumento de gestão dos municípios, organizando a assistência farmacêutica e permitindo um melhor controle interno sobre a compra e dispensação dos medicamentos até o usuário final, evitando desperdícios e atrasos. Mas, com a pressão dos órgãos de controle como a CGU e o TCU, novas ferramentas estão sendo desenvolvidas para possibilitar maior controle sobre o uso dos recursos. Já o PDE Interativo tem seu objetivo totalmente voltado para servir como instrumento de diagnóstico e planejamento das escolas. O controle da execução deste último sistema é realizado apenas pelas prestações de contas relacionadas com o uso dos recursos públicos.

\subsection{Transparência}

Os sistemas de informação analisados teriam um enorme potencial para colaborar com a transparência do uso dos recursos públicos, favorecendo a accountability. Isso decorre de suas capacidades de proporcionarem organização dos dados dos programas governamentais, maior controle sobre o uso dos recursos repassados pelo governo federal e disponibilização dessas informações em base de dados virtuais. No entanto, no Sisjovem e no Hórus não é possível ter acesso aos relatórios específicos do sistema. No caso do PDE Interativo, um usuário pode até ter acesso aos dados do sistema, mas precisa solicitar uma senha ao MEC, o que já 
é um limite. Qual seria o potencial de impacto se as populações locais pudessem ter acesso de forma simples aos relatórios que mostram quais remédios foram comprados e para quais comunidades foram distribuídos? Ou de comunidades escolares entenderem o planejamento de suas escolas e seus principais desafios? Provavelmente facilitaria o controle dos órgãos governamentais e aproximaria os serviços públicos dos cidadãos.

\subsection{Coordenação federativa}

Se os sistemas já são capazes de impactar em algum grau a gestão dos programas no nível local, observou-se que eles ainda não têm tanto impacto como ferramenta de coordenação federativa, tanto como instrumento facilitador do diálogo e construção conjunta de políticas cuja implementação depende de mais de um ente federativo, quanto gerando dados que permitam avaliar as políticas de forma macro, permitindo o replanejamento de suas estratégias de implementação.

Tanto no caso do PDE Interativo quanto no Sisjovem, o monitoramento das secretarias em relação à utilização do sistema pelas escolas e Cras é crucial para os resultados dos programas. As entrevistas realizadas nos estados do Pará e de São Paulo mostram que a atuação das secretarias estaduais e municipais de educação junto às escolas é determinante para o sucesso ou não do planejamento e da execução das atividades do PDE pelas escolas, além de aproximar esses dois atores, que de forma geral ainda não trabalham juntos. No caso da rede estadual de educação de São Paulo, por exemplo, em que o monitoramento do governo estadual praticamente inexiste junto a suas escolas, os resultados do programa são menos potentes.

Já no caso do Sisjovem, as secretarias estaduais têm dificuldades de monitorar os municípios devido a uma falha do sistema que poderia ser solucionada caso houvesse maior diálogo entre os entes federativos. Uma das funcionalidades do sistema é a "gestão preventiva" que deveria indicar pendências dos municípios. Porém, os entrevistados das secretarias estaduais alegaram que o sistema só alerta os casos em que as pendências já aconteceram, impedindo uma atuação de prevenção por parte dos governos estaduais durante o processo de desenvolvimento das atividades.

Mesmo que os sistemas gerem dados relevantes sobre as políticas públicas e populações usuárias, eles ainda não são utilizados pelos gestores dos programas no nível federal ou estadual para auxiliar em ações de melhoria ou planejamento de novas políticas públicas. Existem iniciativas como o caso do PDE Escola mas, de forma geral, as bases de dados centrais, que reúnem as informações enviadas pelos estados e municípios, ainda não possuem instrumentos para gerar relatórios que cruzem dados disponibilizados pelos sistemas permitindo análises sobre a população beneficiada pelos programas e a avaliação de seus impactos globais. No caso do Hórus, as ferramentas que possibilitam o recebimento dos dados imputados pelos municípios pelo governo federal só foram concluídas em 2013, após a finalização desta pesquisa, e por isso não foi possível analisar seus resultados. 
Neste sentido, o CadÚnico, sistema do Programa Bolsa Família integrado a outros sistemas de programas sociais como o Sisjovem, é um caso inspirador. O sistema possui ferramentas que permitem gerar inúmeros indicadores sociais, que são utilizados pelo governo federal e pesquisadores para analisar os impactos do programa e formular novas políticas.

No quadro 3 descreve-se uma comparação resumida dos sistemas estudados com relação a suas respectivas características como instrumento para coordenação federativa, instrumento de gestão e controle, e transparência das políticas públicas.

\section{Resumo dos resultados encontrados}

\begin{tabular}{|c|c|c|c|}
\hline & SISJOVEM & HÓRUS & PDE INTERATIVO \\
\hline $\begin{array}{l}\text { coordenação } \\
\text { federativa }\end{array}$ & $\begin{array}{l}\text { Possibilita a comunicação entre } \\
\text { entes federativos, mas tem falhas } \\
\text { nesse quesito, pois o acesso } \\
\text { aos dados do sistema é restrito } \\
\text { para municípios e estados. Um } \\
\text { dos problemas é a dificuldade } \\
\text { de monitoramento dos estados } \\
\text { devido à restrição de acesso a } \\
\text { alguns dados. }\end{array}$ & $\begin{array}{l}\text { Apenas a partir de } 2013 \\
\text { serão desenvolvidas } \\
\text { ferramentas que permitirão } \\
\text { o envio e análise dos } \\
\text { dados pelo governo } \\
\text { federal. }\end{array}$ & $\begin{array}{l}\text { O acompanhamento e a avaliação } \\
\text { dos planos escolares são realizados } \\
\text { por todos os entes federativos. } \\
\text { Apesar de secretarias municipais e } \\
\text { estaduais terem o papel de monitorar } \\
\text { as escolas de suas redes de ensino, } \\
\text { percebeu-se que os estados têm } \\
\text { dificuldade de monitorar as escolas } \\
\text { de suas redes e que os estados não } \\
\text { auxiliam as secretarias municipais. }\end{array}$ \\
\hline $\begin{array}{l}\text { gestão ao nível } \\
\text { local }\end{array}$ & $\begin{array}{l}\text { Com algumas limitações, pois seu } \\
\text { desenho foca mais o controle do } \\
\text { que os processos de gestão. }\end{array}$ & $\begin{array}{l}\text { Possibilita o controle de } \\
\text { estoque e dispensação de } \\
\text { medicamentos. }\end{array}$ & $\begin{array}{l}\text { Possibilita que as escolas construam } \\
\text { seus diagnósticos e planejamentos, } \\
\text { os municípios constroem uma gestão } \\
\text { escolar mais próxima à realidade das } \\
\text { escolas. }\end{array}$ \\
\hline $\begin{array}{l}\text { ferramenta de } \\
\text { controle }\end{array}$ & $\begin{array}{l}\text { O grande objetivo do sistema } \\
\text { é controlar a implantação do } \\
\text { programa por meio do envio } \\
\text { de frequência dos jovens } \\
\text { nas atividades do Projovem } \\
\text { Adolescente. }\end{array}$ & $\begin{array}{l}\text { Sistematiza a entrada e a } \\
\text { saída de medicamentos, } \\
\text { controla o processo } \\
\text { de distribuição de } \\
\text { medicamentos, reduzindo } \\
\text { desvios e desperdícios. }\end{array}$ & $\begin{array}{l}\text { Não é o objetivo principal do sistema. } \\
\text { Mas, no caso daquelas escolas } \\
\text { que recebem recurso, é realizada } \\
\text { prestação de contas que comprova } \\
\text { se o que foi estabelecido no plano foi } \\
\text { cumprido ou não. }\end{array}$ \\
\hline $\begin{array}{l}\text { transparência aos } \\
\text { cidadãos }\end{array}$ & $\begin{array}{l}\text { É fechado e nem os estados ou } \\
\text { municípios têm acesso a todos } \\
\text { os dados. }\end{array}$ & $\begin{array}{l}\text { Permite apenas acesso dos } \\
\text { gestores. }\end{array}$ & $\begin{array}{l}\text { Acesso é restrito aos gestores, } \\
\text { mas futuramente será aberto aos } \\
\text { cidadãos. }\end{array}$ \\
\hline
\end{tabular}

Fonte: Elaboração própria.

\section{Conclusão}

Os sistemas de informação têm sido cada vez mais utilizados como importantes ferramentas de políticas públicas, especialmente quando há necessidade de maior controle da execução das políticas públicas, como no caso de países federativos. Quando bem desenvolvidos, com 
participação efetiva dos principais atores envolvidos no processo, esses sistemas têm um grande potencial para serem utilizados como ferramentas de coordenação federativa, diagnóstico, planejamento, avaliação e produção de dados e informações para novas formulações e planejamentos de políticas públicas.

Este artigo contribui com o estudo do emprego de sistemas de informação no setor público, em particular, com aqueles que são desenvolvidos em torno de políticas públicas específicas. Propomos a utilização de um referencial teórico baseado num modelo que combina abordagens de social construtivismo, contextualismo e estruturacionismo em sistemas de informação para descrever como três sistemas em áreas sócias distintas são projetados na esfera federal e incorporados em outras esferas de governo, articulando a coordenação federativa entre elas.

Sistemas de informação buscam, de forma geral, uma leitura comum entre muitos processos distintos. Isso é positivo, na medida em que pode colaborar com o controle e a geração de indicadores importantes para a avaliação das políticas. Mas em um país tão grande e diverso como é o Brasil, é preciso que se tenha em mente que essas generalizações podem encobrir ou ignorar diferenças que são fundamentais para os resultados que se pretende atingir. Para tentar não cair nesse perigo, seria preciso que os sistemas fossem criados de forma participativa, e que houvessem espaços permanentes de diálogos entre os diversos atores envolvidos na implementação das políticas e no uso do sistema.

No entanto, percebe-se que os sistemas de informação estudados refletem, de forma geral, a forma como o federalismo brasileiro está organizado. Nossas conclusões demonstram que, na prática, a falta de articulação entre as diferentes esferas de governo, particularmente aquela que propõe as políticas sociais e aquelas que são responsáveis por sua implantação, produz sistemas de informação menos efetivos para a gestão e mais focados no controle das ações dos entes federados. Os processos de desenvolvimento ainda estão muito centralizados no governo federal, e há pouco espaço para o diálogo com os municípios e estados, atores responsáveis por sua utilização, seja no momento de concepção ou ao longo de sua utilização.

Talvez por isso, o PDE Interativo tenha se destacado entre os sistemas estudados. Ele proporcionou maior espaço de diálogo com os municípios e estados ao longo de seu desenvolvimento e implementação. Além disso, seu formato é mais aberto, permitindo que os usuários especifiquem seus casos e, por consequência, alcancem resultados mais responsivos a suas necessidades.

Mas é preciso reconhecer que os sistemas têm limites, e que é preciso ter funcionários bem treinados, que possam julgar as respostas, auxiliar o preenchimento e verificar situações em que o sistema não está sendo responsivo. Como são os municípios e estados os responsáveis por utilizar os sistemas e implementar as políticas públicas, é preciso que o governo federal reconheça seu papel, não apenas como responsável por operacionalizar os sistemas, mas como ator do processo.

No caso do PDE, como já afirmado, o papel das secretarias de educação é fundamental para que se garantam bons resultados ao Programa. No caso do Sisjovem, o fato de ele ser composto basicamente por campos fechados diminui muito seus resultados como sistema de 
gestão e não permite que se compreendam os verdadeiros resultados e dificuldades da política. Mesmo como ferramenta de controle, sem a ausência de um funcionário capacitado, ele pode ser falho. O mesmo acontece com o Hórus: o sistema por si só não é capaz de inibir problemas, é preciso que haja o monitoramento constante de funcionários. Neste sentido, ressalta-se a importância de maior diálogo e maior capacitação para os estados e municípios, para que sejam de fato corresponsáveis pelos sistemas.

A ampla utilização dos sistemas como uma ferramenta de coordenação federativa no governo federal brasileiro é algo recente e esta pesquisa mostrou que a participação dos atores de outros níveis federativos no processo de desenvolvimento e regulamentação de sistemas acoplados a programas sociais propostos pelo governo federal ainda é baixa, o que por vezes pode resultar em sistemas rígidos ou não tão efetivos.

Algumas escolhas feitas nessas etapas podem dificultar o uso do sistema, porque esbarram em problemas como falta de capacidade técnica dos funcionários responsáveis pela implantação ou infraestrutura deficiente dos municípios brasileiros, que ainda possuem equipamentos públicos com poucos computadores e conectividade ruim ou inexistente. A opção por sistemas $100 \%$ on-line, por mais moderna que seja, exclui usuários ou dificulta o trabalho em grande parte dos municípios brasileiros. Além disso, os dados gerados são pouco utilizados para avaliação e planejamento dos programas, e os sistemas praticamente não atuam como ferramentas de accountability.

Neste estudo ouvimos diversos atores envolvidos no processo de desenvolvimento e implantação de sistemas que acompanham políticas públicas federais que devem ser efetivados por outras esferas de governo, e identificamos elementos em que o processo de comunicação entre as partes é falho, resultando em processos que estão aquém do que poderia ser alcançado em termos de coordenação federativa. A partir deste artigo, gestores públicos podem avaliar melhor os problemas envolvidos no processo de criação de sistemas que acompanham as políticas públicas federais, e podem obter melhores resultados em termos de transparência, controle, processos de gestão e coordenação federativa, caso invistam em maior participação de todas as partes envolvidas neste processo de desenvolvimento. Para pesquisadores interessados em investigar o uso de sistemas de informação no setor público, apresentamos a aplicação de um referencial teórico que pode ser útil em várias situações que envolvam a participação de atores em diversos níveis que devam trabalhar de forma integrada para a implantação de sistemas de informação.

\section{Referências}

ABRUCIO, Fernando; PEDROTI, Paula; PÓ, Marcos. A formação da burocracia brasileira: trajetória e significado das reformas administrativas. In: LOUREIRO, Maria Rita; ABRUCIO, Fernando Luiz; PACHECO, Regina Silvia. Burocracia e política no Brasil: desafios para a ordem democrática no séc. XXI. Rio de Janeiro: FGV, 2010. p. 27-72. 
ARRETCHE, Marta T. S. Mitos da descentralização: mais democracia e eficiência nas políticas públicas? Revista Brasileira de Ciências Sociais, v. 11, n. 31, p. 44-46, jun. 1996.

BIJKER, Wiebe E.; LAW, John. Shaping technology/building society: studies in socio-technical change. Cambridge, MA: MIT Press. 1992.

BOVENS, Mark; ZOURIDIS, Stavros. From street-level to system-level bureaucracies: how information and communication technology is transforming administrative discretion and constitutional control. Public Administration Review, v. 62, n. 2, p. 174-184, mar./abr. 2002.

BRASIL. Portaria no $\mathbf{8 4 8}$, de 28 de fevereiro de 2010. Disponível em: <www.mds.gov.br/acesso-ainformacao/legislacao/assistenciasocial/portarias/2010/Portaria_MDS_no_848_de_28-12-2010. pdf $>$. Acesso em: 11 fev. 2013.

BRASIL. Portaria no 4.217, de 28 de dezembro de 2010. Disponível em: < http://portal.saude.gov. br/portal/arquivos/pdf/Portaria_MS_4217_28_12_2010.pdf>. Acesso em: 11 fev. 2013.

BRESSER-PEREIRA, Luiz Carlos. Democracia, estado social e reforma gerencial. Revista de Administração de Empresas, v. 50, n. 1, p. 112-116, jan./mar. 2010.

DINIZ, Eduardo H. et al. O governo eletrônico no Brasil: perspectiva histórica a partir de um modelo estruturado de análise. Rev. Adm. Pública, v. 43, n. 1, p. 23-48, jan./mar. 2009.

GOERTZ, Gary; MAHONEY, James. Negative case selection: the possibility principle. In: GOERTZ, Gary. Social science concepts: a users guide. Nova Jersey: Princeton University Press, 2006. p. 177210.

JAYO, Martin. Correspondentes bancários como canal de distribuição de serviços financeiros: taxonomia, histórico, limites e potencialidades dos modelos de gestão de redes. Tese (doutorado) — Escola de Administração de Empresas de São Paulo, Fundação Getulio Vargas, São Paulo, 2010.

JAYO, Martin; DINIZ, Eduardo H. Uso de correspondentes bancários pelos bancos brasileiros: um mapeamento dos modelos de gestão de redes. In: ENCONTRO NACIONAL DE PÓS-GRADUAÇÃO EM ADMINISTRAÇÃO, XXXIV, 2010, Rio de Janeiro. Anais... Rio de Janeiro: Anpad, 2010. p. 157175.

JORNA, Frans; WAGENAAR, Pieter; Discretion and digital discipline. Public Administration, v. 85, n. 1, p. 189-214, 2007.

LIPSKY, Michael. Street level bureaucracy: dilemmas of the individual in public services. Nova York: Russell Sage Foundation, 1980.

MINISTÉRIO DA SAÚDE. Disponível em: <http://portalsaude.saude.gov.br/portalsaude/index. cfm>. Acesso em: 30 set. 2012.

OBINGER, Herbert; LEIBFRIED, Stephan; CASTLES, Francis G. Introduction: federalism and welfare state. In: OBINGER, Herbert; LEIBFRIED, Stephan; CASTLES, Francis G. (Ed.). Federalism and the welfare state: new world and European experiences. Cambridge: Cambridge University Press, 2005. p. 1-64. 
ORLIKOWSKI, Wanda J. Using technology and constituting structures: a practice lens for studying technology in organizations. Organization Science, v. 11, n. 4, p. 404-428, ago. 2000.

PETTIGREW, Andrew M. Longitudinal field research on change: theory and practice. Organization Science, v. 1, n. 3, p. 267-292, ago. 1990.

PLANO DE DESENVOLVIMENTO DA ESCOLA. Disponível em: < http://pdeescola.mec.gov.br/> . Acesso em: 15 set. 2012.

POZZEBON, Marlei; DINIZ, Eduardo H. Theorizing ICT and society in the Brazilian context: a multilevel, pluralistic and remixable framework. BAR. Brazilian Administration Review, v. 9, n. 3, p. 287-307, jul./set. 2012.

POZZEBON, Marlei; DINIZ, Eduardo H.; JAYO, Martin. Chapter II: Adapting the structurationist view of technology for studies at the community/societal levels. In: DWIVEDI, Yogesh K. et al. (Ed.). Handbook of research on contemporary theoretical models in information systems. Hershey, PA: IGI Global, 2009. p. 18-33.

ROCHA, Carlos V.; FARIA, Carlos A. P. de. Cooperação intermunicipal, reterritorialização da gestão pública e provisão de bens e serviços sociais no Brasil contemporâneo: a experiência dos Consórcios de Saúde de Minas Gerais. Cadernos Metrópole, n. 11, p. 73-105, 2004.

SOUZA, Celina. Governos e sociedades locais em contextos de desigualdades e de descentralização. Ciência e Saúde Coletiva, v. 7, n. 3, p. 431-442, jul. 2002.

THURSTON, Anne. Public records: evidence for openness. Institute of Commonwealth Studies School of Advanced Study, University of London, 2012. Disponível em: <http://blogs.estadao.com.br/ publicos/files/2012/08/Public-Records-as-Evidence-for-Openness-FINAL.doc_pdf $>$. Acesso em: 14 ago. 2012.

WALSHAM, Geoff. Cross-cultural software production and use: a structurational analysis. MIS Quarterly, v. 4, n. 26, p. 359-380, dez. 2002.

Lya Cynthia Porto de Oliveira é doutoranda em administração pública e governo pela Escola de Administração de Empresas de São Paulo, Fundação Getulio Vargas. E-mail: lyaporto2@gmail.com.

Sarah Martins Faleiros é mestre em administração pública e governo pela Escola de Administração de Empresas de São Paulo, Fundação Getulio Vargas, e analista da Oficina Municipal — Escola de Cidadania e Política. E-mail: safaleiros@gmail.com.

Eduardo Henrique Diniz é professor na Escola de Administração de Empresas de São Paulo, Fundação Getulio Vargas. E-mail: eduardo.diniz@fgv.br. 